Journal of Environmental Sciences (JES)

Institute of Environmental Studies and Research, Ain Shams University

Altuhoo,.et al.

\title{
A SYSTEM OF GREEN ROOFS IN INFORMAL HOUSING AREAS AN APPLIED STUDY ON JLEEB AL-SHUYOUKH
}

\author{
Ali M. Ali H. Altuhoo \\ National Authority for Applied Education and Training
}

\begin{abstract}
Informal housing areas are known for their high building density, which is a prevalent phenomenon in urban societies in the developing world, as urban growth is irregular. So, these areas grow at high rates within cities, where their environment lacks the most important components, which are the green spaces that represent the natural lung of the city in addition to the functional and social value represented in popular culture.

This research drives at contributing at solving the problem of the rareness of green spaces in the informal housing areas by adopting an approach that depends on green planes as a practical solution to compensate for the loss in green areas and create new job opportunities that generate profit for the people of those areas with low income; including as well, the electric power generation system through solar panels which will have an economic and environmental impact and ensure sustainability.

The Results of the study found the positive impact of green roofs in rationalizing electricity consumption, reducing building heat, and beautifying the environment in general for the building.

Keywords: Green surfaces - Informal - Random surfaces - Air pollution Positive green roof - Temperature reduction - Thermal Island.
\end{abstract}

\section{INTRODUCTION}

The rapid increase in construction activity at the end of the last century came as a result of the increased demand for housing units to provide shelter, and the state's failure to fulfil its duty to set urban development plans in areas within cities, leaving the matter to the private sector to meet the community's 
Journal of Environmental Sciences (JES)

Institute of Environmental Studies and Research, Ain Shams University

Altuhoo,.et al.

need of housing units. This led to a huge shortage of basic services, entertainment and recreational services, due to the private sector's exploitation of the entire area in construction, leaving behind huge quantities of concrete blocks. As a result, negative changes led to high temperatures inside cities, causing high pollution and environmental problems due to the overlap of various residential, industrial and commercial activities, the use of environmentally harmful manufacturing materials and the lack of suitable places such as green roofs, which act through purifying the air, reducing the temperature, humidifying and renewing the air inside cities.

It is worth mentioning that $82 \%$ of the industrialized world now are living in cities that create many environmental problems that have been exacerbated by removing vegetation cover to accommodate urban expansion; added to that, the construction and demolition operations contribute to $40 \%$ of global thermal emissions. (Martinant, 2021)

All of the previously mentioned has led to our need to form an activity, a change or merge sustainable practices in our cities to reduce environmental problems and overcome the negative effects that work on the psychological imbalance of urban residents as a result of the lack of green spaces, that can be consistent with their recreational and entertainment culture. This is reflected in its productive and creative capacity and innovation in society and loads it with environmental hardship and burden that creates its lack of visual, thermal and psychological comfort. Consequently, it has been necessary to detect a unique way of its kind and integrate it within the existing 
architectural design that can overcome many of the challenges produced by urbanization.

\section{RESEARCH PROBLEM}

1-The density of the built environment in the informal housing areas and the scarcity of lands leads to a decrease in opportunities of providing green spaces compared to other priorities such as (providing schools, hospitals, public service places, etc.).

2-Designing an approach that contributes to creating green areas within the informal areas and achieve sustainability.

3-Overcoming the random image of building rooftops in the informal areas of the capital.

4-Increasing the area of the green space in the capital that suffers from the increasing pollutants.

\section{STUDY SIGNIFICANCE}

The significance of the study emerges currently from the erosion of green areas inside the capital because of the growing expansion movement in the roads that have led to the erosion of $38 \%$ of the green areas.

Thus, the study spotlights the importance of implementing a strong alternative that achieves sustainability and makes the environment valid and fit; in addition to that green places are linked to popular culture that achieves social communication and meets their non-material needs in entertainment. 


\section{STUDY OBJECTIVES}

1- The Main Objective: Creating sustainable green spaces within the urban space in informal residential areas without the cost of removing buildings in a short time by using the rooftops in those areas.

\section{2- The Secondary Objectives:}

A. Elimination of visual pollution on the roofs of the housing buildings in those buildings in the capital.

B. Focusing on the economic return for achieving sustainability.

C. Fulfilling the social requirements by providing green spaces that represent entertainment in popular culture.

\section{RESEARCH QUESTIONS}

The research seeks to answer many questions for checking the validity of the hypotheses, as follows:

1- Is there practical feasibility of using the green spaces system for the rooftops in the informal areas?

2- Are there any economic returns that can be achieved to ensure sustainability?

3- Are there multiple requirements to ensure the functional sustainability of green spaces? 


\section{RESEARCH METHODOLOGY}

\section{The research relies on two main approaches as follows:}

- The Analytical Theoretical Approach: This method exposes and analyzes green roofs, their definition, importance, types, types of plants that suit the Kuwait environment, the environmental benefits of the green roofs, the pros and cons, and the use and review of researches, theses, studies and scientific books dealing with the subject of study.

- The Case Study Methodology: This research is based on the qualitative approach, which is based on analysis of data according to the inductive approach, to expose negatives and positives, maximizing them and provide the learned lessons from that experience that creates a positive environment.

\section{The Concept of Green Roofs:}

It is the transformation of deformed or unused surfaces into a viable and valuable area of private and public green spaces that improve air quality and life together. (Jorgensen, 2009)

\section{A) Types of green roofs: (Sabiha, 2010)}

1. Wide Green Roofs: This type of green roofs has low natural maintenance; it is also light in weight and has a thin or shallow layer of a growing substrate of about $200 \mathrm{~mm}$. or less. The green roof type generally has lower water requirements and suitable for small and low-growing plant types such as Succulents. 
Journal of Environmental Sciences (JES)

Institute of Environmental Studies and Research, Ain Shams University

Altuhoo,.et al.

Extensive green roofs are specially planted and designed to increase the diversity of native plants and provide habitat including food and shelter for some wildlife such as birds. Moreover, the extensive green roofs can also be referred to as ecological or biologically diverse roofs, because they are less expensive to install and commonly used for their primary environmental advantages.

2- The Intensive Green Roofs: the intensive type is generally heavier and has a deeper layer than the growing substrate, and also supports a wider range of plant types. It can be easily accessed by people because they usually support heavyweights. Intensive green surfaces require more maintenance and watering and usually referred to as roof gardens. The reason for this is that they are specially installed on highly engineered landscaping, which also qualifies them to be part of urban farming. Consequently, the intense green roofs can preserve shrubs, trees and benches.

3- The Vital Green Roofs: This is a modern addition to the types of green roofs - especially, for their nature in incorporating green roofs and solar panels. By using a modern design and perfect fashions, the vital green roofs could be considered an improved version of the regular green roof combined with solar energy technologies, as they are simply designed to enhance biodiversity and increasing the amount of solar energy extracted from green roofs at the same time. 
B) The environmental benefits of green roofs: (Yunus, 2017)

1- Long-Lasting Roof: Generally green roofs protect the actual roof and its membrane from harsh weather and UV rays. As such, green roofs help keep the roof up to twice the life of traditional roofs.

2- Provides Insulation for Rainwater: Green roofs absorb rainwater through plants, drainage layer and substrate layer, as it delays the drainage of rainwater into the sewage system. It also purifies rainwater and allows water to evaporate through plants, which helps stabilize the groundwater level. Additionally, it also reduces peak loads on the sewage system, and thus reduces flood risks.

3- Air Purification: Green roofs filter particles from the air and convert carbon dioxide into oxygen. Therefore, green roofs contribute to purifying the air, which enhances the overall air quality.

4- Increase Efficiency of Solar Panels: Green roofs reduce rooftop temperatures; so, the achieved cooled roof becomes ideal for solar panels which become more efficient. Thus, the total energy costs reduce.

5- Reducing the Ambient Temperature: Plants absorb about 50\% of the sunlight and reflect about $30 \%$ of it, and this process creates a cooler and more pleasant climate, and with green roofs in the city, the total temperature in the city will decrease by about 3 degrees Celsius. 
Journal of Environmental Sciences (JES)

Institute of Environmental Studies and Research, Ain Shams University

Altuhoo,.et al.

6- Increasing biodiversity: The plants on the roof of the building enhance the habitats of birds, insects and butterflies. The plants also differ from one surface to another, which means that they may improve and increase the biodiversity of the city.

7- Establishing A Healing Environment: Green roofs are responsible for green spaces, which encourages patients to recover faster, and a green environment is also known as a healing environment because it increases pain tolerance, which means that patients recover more quickly - and stay in hospitals for less time.

8- Soundproofing: The sound is to be insulated, as the soundproofing's thickness over the concrete surface is not less than $12 \mathrm{~cm}$, thus, it becomes soundproofing and reduces the sound by $40 \mathrm{DB}$.

\section{- Plants that can be grown on rooftops in Kuwait:}

Medicinal and aromatic plants: Such as (mint - basil - oregano - rosemary thyme).

Ornamental plants and cut-flowers: Including (Cloves - Gerbera - Pots Senjonim - Gardenia - Garrotia - Flange)

Fruit Trees: regarding the fruit trees, only types that can be grown is controlled are used by the pruning process, they include (Lemon, grapes, peaches, apples, and tangerines). 


\section{The effect of the size and density of the urban cluster on the temperature of urbanization compared to green spaces: (Ibrahim, 2014)}

Figure No. (1) Shows a comparison of the temperature effect between urban and green areas. The phenomenon of thermal islands is evident in the areas in which they are overcrowded with urban mass, i.e. the figure (1) shows the clear difference between the high temperatures above the urban mass and low temperatures in cultivation areas and the wide difference in the city Centre in particular.

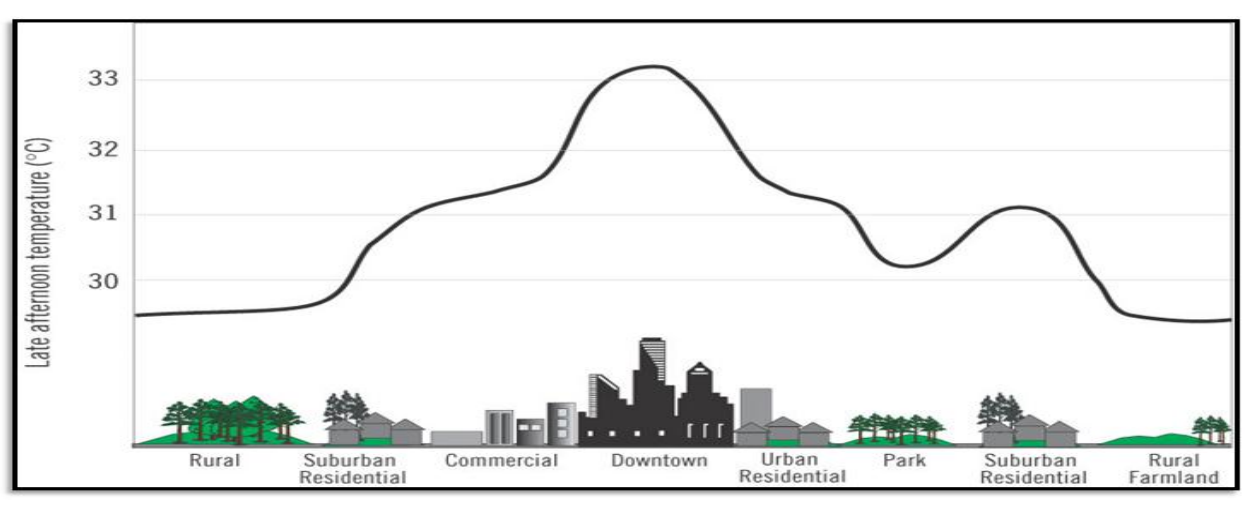

\section{The effect of the air movement on the building mass:}

Figure (1) shows the movement of air, its flow and its effect on the urban structure. The rate of change of air inside a city decreases the more the structural density increases and the buildings rise. A city like Shanghai in China reaches a re-change cycle of air for three days, while the re-change cycle of air in the city of Rabat, Morocco reaches about one day and a half 
due to the low rise of the floors in this city. This raises the temperature in addition to loading the air with the density of pollutants and its saturation. Figure No. (1) Shows the effectiveness of green spaces in purifying the air from pollutants and thus humidifying the air.

\section{Air movement and its effect on urban formation}

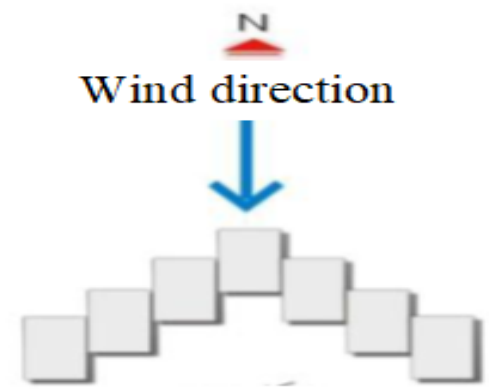

Less wind use

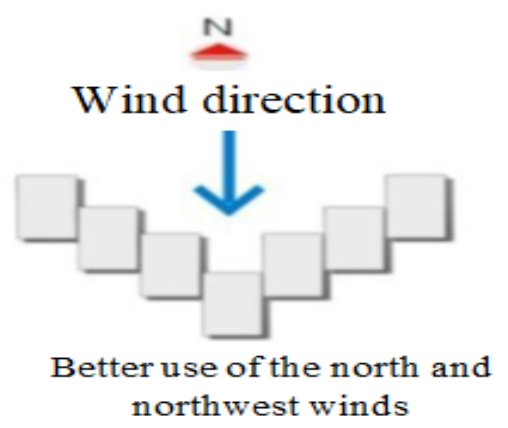

northwest winds

Figure No. (1): Effectiveness of green spaces in purifying the air from pollutants and thus humidifying the air (Martinant, 2021)

Figure No. (2): The movement of air and its effect on the urban mass (Shishegar, 2013) 

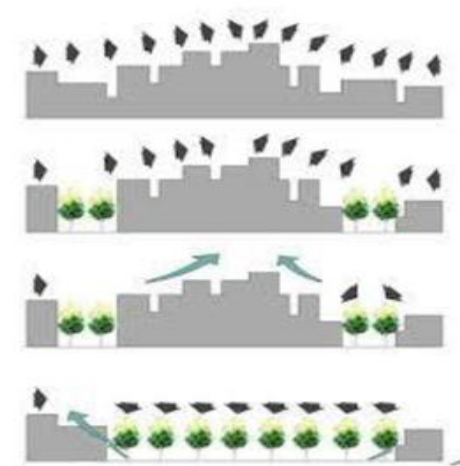

The effect of afforestation in the city center to moderate the weather

Figure No. (3): The effect of afforestation processes on mitigating the weather (Shishegar, 2013)

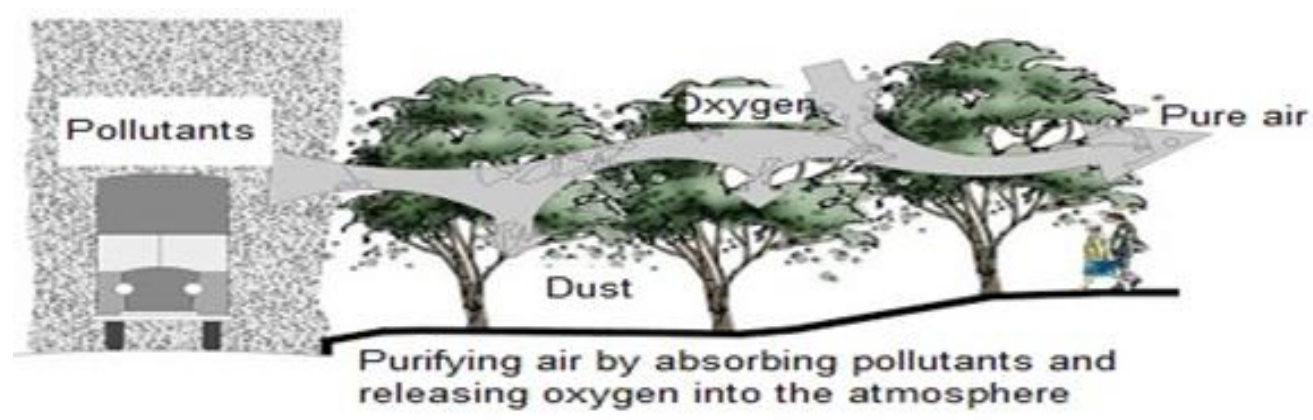

Figure No. (4): This figure shows the absorption of pollutants across the green surfaces (Jorgensen, 2009)

\section{3- The effect of raw materials used on urban surfaces:}

All modern materials used in the construction of buildings harm the absorption of temperatures. Figure No. (5) Shows the difference in temperature degrees on the normal concrete surface and the roof with layers 
of agriculture. In addition to the solar radiation falling on the roofs which increases the feeling of temperatures, the green surfaces add the feeling of thermal comfort and non-suffocation with natural pollutants. Moreover, all the newly used raw materials conduct the thermal conductivity and reflect the heat. So, the person feels that the natural temperature rise by about five degrees outside the building and 10 degrees inside it. In addition to that, colours also have an effective effect on heat-absorbing or its reflection on the built urban environment.

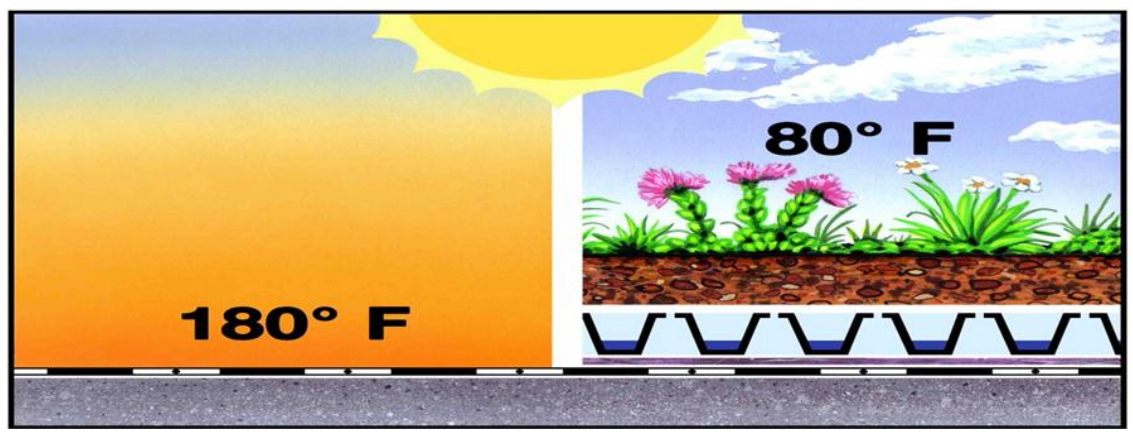

Figure No. (5): Shows the effect of temperature on the surface without and by green areas (Beer, 1990)

\section{Case Study of (Jleeb Al-Shuyoukh):}

Jleeb Al-Shuyoukh is an area belonging to the Farwaniya Governorate in the State of Kuwait, and it is one of the oldest areas in the State of Kuwait, 13 $\mathrm{km}$ southwest of the capital, and in the past, it was a desert area with many wells. 
The population of the Jleeb Al-Shuyoukh area is (344) thousand people, according to the census (2020) (Kuwait Civil Information Authority), which makes Jleeb Al-Shuyoukh the largest Kuwaiti area in terms of population, and it is the largest slum city where foreigners are present. Long live the workers.

This area is characterized by randomness, due to the spread of foreign workers in it for housing or work, and the area has lost its aesthetic character and the low environmental level, and the state's efforts to develop that area have failed, due to a large number of residents in it, in addition to the large area, which may cost a lot of Funds.

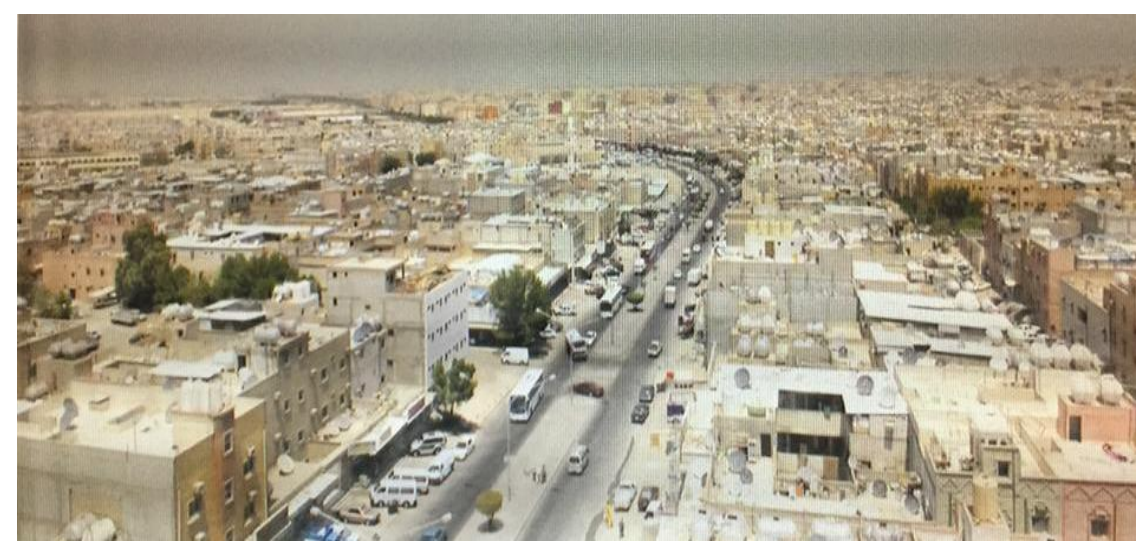

Figure No. (6): Shows the study area, its building mass, and the absence of voids (the State of Kuwait, 2021)

The Features of the existing urbanization or urban fabric is dominated by the accumulation of buildings next to each other without the slightest joints that reduce the speed of the air. The widths of the streets are narrow, ranging 
Journal of Environmental Sciences (JES)

Institute of Environmental Studies and Research, Ain Shams University

Altuhoo,.et al.

between 2: 4 meters; so that, they do not allow part of them to be exploited for forestation; in addition to the absence of any spaces that allow the existence of green surfaces in the area, which leads to concentrate most of the factors causing pollution. The accumulation of garbage, old things, dirt and building debris appears on the roofs of houses in those areas, which leads to their containment of rodents, reptiles and insects as a safe environment for them, which are essential factors for diseases transmission to humans in case of direct contact with them or their offal.

The overlap between residential, commercial and industrial activities is a major cause of a high percentage of air pollution, in addition to burning a percentage of waste due to the presence of many popular markets in the area crowded with foreign workers.

The region faces many problems that cannot be ignored, chief among them the environmental, economic and social marginalization. This is evident through buildings, random markets and crowded streets, and this is evidenced by the high unemployment rate in the region, which is an ideal area for study to experiment with creating new job opportunities based on the shift to the green zone in clearing the roofs of homes from garbage and replacing them by planting roofs with different plants.

\section{Reasons for Choosing the Study Area:}

1. The problem of urban congestion is strongly manifested in that region.

2. No green spaces or any void spaces suitable for creating green spaces.

3. The condition of the buildings is viable for testing. 
4. The social and financial level of the people in this district is below the average.

5. The ease of influence on the local community and its acceptance of the idea through the NGOs existed in that area and establishing a guiding model for its people.

\section{Results and Recommendations:}

1. The roofs of residential buildings can be cultivated by providing awareness and promotion for the cultivation of plants that can achieve an economic profit by generating income for property owners, especially, when most of the property owners are the same family.

2. The presence of many civil societies in the area can be attracted to promote and attract people to the idea of surface crops cultivation to achieve a profitable return, which brings income to families in addition to the little required care, so these societies act as a guiding model.

3. The green roof system can be supported in these areas through the NGOs that operate in the area, especially, that they support micro-enterprises to reduce unemployment. in this area.

4. Green spaces are a practical and positive solution for limiting the negative impact of the built environment and the higher levels of air pollution, as well as the high temperature.

5. Green areas will achieve the following dimensions: 
The Economic Dimension: By reducing the unemployment rate and increasing family income.

The Social Dimension: It will reduce the environmental burden and improve the psychological and social balance of the individual in these areas, according to their compatibility with the popular culture for leisure and recreation. This Promotes cooperation and creates a successful society.

\section{The Environmental Dimension:}

- The individual should have a proportion of the green areas.

- Improving the built environment by improving air quality and eliminating rodents and pathogenic reptiles.

- Decrease the temperature in the DC.

- Creating a lung that works on purifying air for the intersection of residential, industrial and craft activities.

\section{The Urban Dimension:}

- Improving the visual image of the urban mass.

- The optimum utilization of the currently horizontal architectural spaces, and later, the vertical ones.

- Improving the image of the general location of the capital's urban mass.

\section{The state must implement the following:}

1. Activating the role of civil societies in the informal areas for their direct interaction with the local community; identifying as well, its behavior, requirements, and ways of orientation. 
2. Providing direct financial support for the requirements of planting green roofs to reduce costs and attract the largest possible number of individuals.

3. Activating the Green Building Code for its importance in achieving sustainability and consolidating the concept of green architecture.

\section{REFERENCES}

Beer. B., (1990). Environmental Planning for Site Development, Clays Ltd, Press, England.

Ibrahim. A., (2014). Analytical Study to Measure the Efficiency of the Environmental Performance of Residential Communities In Egyptian Cities (Analytical Study of Some Models of Residential Communities In Egypt), M.A. Thesis, Faculty of Engineering, Cairo University, Cairo.

Jorgensen. A., (2009). Evaluating the Benefits of Urban Green Space Progressing The Research Agenda (Unpublished Manuscript), U.K.

Martinant. $\quad$ F., (2021). Urban Development, https://www.worldbank.org/en/topic/urbandevelopment/overview $(2 / 6 / 2021)$

Sabiha. W., (2010). The Concept of Green Spaces, Within the Scope of the Constructed Environment, PhD. Thesis, Faculty of Engineering, Cairo University, Cairo.

Shishegar. N., (2013). Street Design and Urban Microclimate, Street Design and Urban Microclimate: Analyzing the Effects of Street Geometry and Orientation on Airflow and Solar Access in Urban Canyons, Journal of Clean Energy Technologies, Vol. (1), No. (3), pp. 52-56. 
State of Kuwait (2021) : Jleeb Al-Shuyoukh, Kuwait Government Online,

Kuwait, https:// www. e.gov. kw/ sites/ kgoenglish /

Pages/HomePage.aspx $(20 / 6 / 2021)$

Yunus. A., (2017). The Importance of Green Space and Its Design Systems In Cities, Vo. (3), No. (2), Environment Journal, Ain Shams University, Cairo.

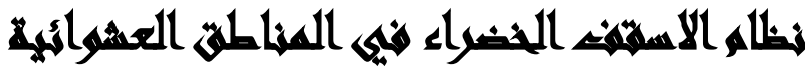

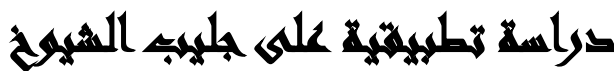

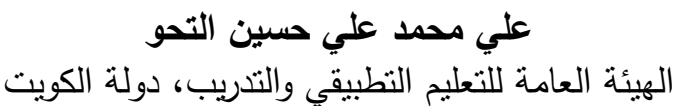

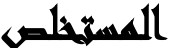

تشتهر مناطق الاسكان غير الرسمي بارتفاعات غير منتظمة، وهي ظاهرة منتشرة في

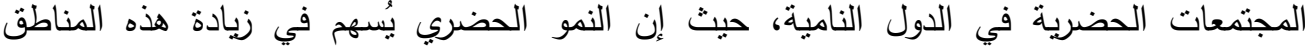

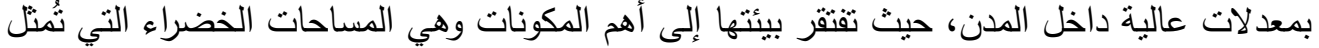

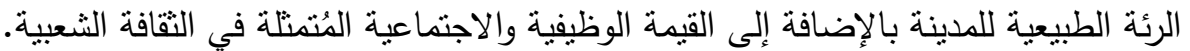

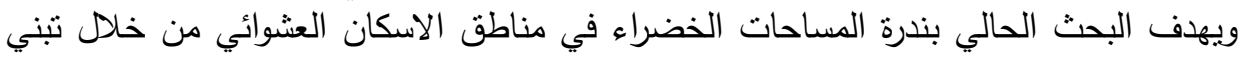

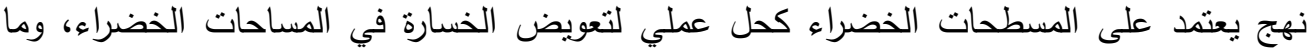

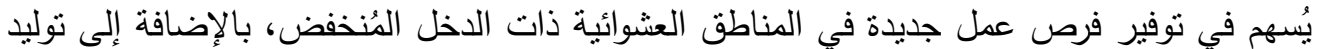

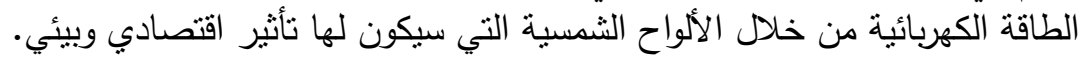
وتقوم الدراسة بتطبيقه في منطقة تُعد من أكبر المناطق العشوائية وهي منطقة جليب الثيوخ في لئي وتوصلت نتائج الدراسة إلى الأثر الإيجابي للأسقف الخضراء في ترشيد استهلاك الكهرباء

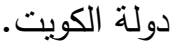

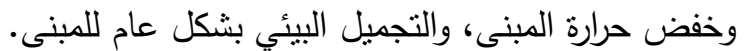
الكلمات المفتاحية: الاسطح الخضراء - المناطق العشوائية - تلوث الهواء - الاسطح الخضراء -

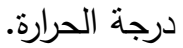

